\title{
An investigation of virgin variation of branching pattern of ECA and CCA: a case report
}

\author{
RAJANI, S. * \\ Department of Anatomy, All India Institute of Medical Sciences, Rishikesh, Uttrakhand, India \\ *E-mail: nani_sahayal@rediffmail.com
}

\begin{abstract}
Introduction: Common carotid and its two major branches, external and internal carotid arteries form arterial network for blood supply in the head and neck region. Variations in configuration and branching pattern of these arteries change the irrigation pattern and complicate the identification of specific arteries during surgical intervention coupled with imagery interpretation for diagnosis. Though handful variations have been documented yet there is strong need to report unusual, new and virgin organization of configuration and branching pattern in these arteries. Case Report: During dissection of head and neck region, anomalous branching pattern consisting of bilateral trifurcation/quadrification of common and external carotid arteries and abnormal trifurcation of distal external carotid artery was observed. Conclusion: Lack of knowledge of these variants in branching configuration may lead to unfortunate differential diagnosis and iatrogenic complications.
\end{abstract}

Keywords: common carotid, external carotid artery, quadrification, trifurcation, branching pattern.

\section{Introduction}

The common carotid artery (CCA) bifurcating into external and internal carotid arteries at the level of superior border of thyroid cartilage in carotid triangle (STANDRING, 2008 ) plays major role for blood supply to the head and neck region. External carotid artery (ECA) gives off eight branches terminating into superficial temporal and maxillary arteries, lies anteromedially to the internal carotid artery (ICA) at origin in the carotid triangle. ECA provides vascular supply to the structures of head and neck (DATTA, 1989).

The variations in the branching pattern of the carotid arteries (CCA/ECA) are well known and documented. These variations are higher or lower bifurcations of CCAs. The bifurcation can occur as high as the hyoid bone or even the styloid process, or as low as the cricoid cartilage (HUBER, 1982). But the present study detected simultaneously occurring bunch of new variations in branching pattern of CCA/ECA. These anatomic vascular variations are essential for differential diagnosis and surgical approaches in the head and neck region (POYNTER, 1992). The branches of ECA are the key landmarks for adequate exposure and appropriate placement of cross clamps on the carotid artery. So the knowledge of variations in branching pattern of carotid arteries is useful to minimize the postoperative complications and in making bloodless surgical field (HAYASHI, HORI, OHTANI et al., 2005). Therefore, the case is reported not only for its unique virgin and altogether new anatomical variants in bilateral branching pattern of CCA and ECA as far as known to author but also for its usefulness to clinicians/surgeons in diagnosis and surgical treatment and imagery interpretation.

\section{Case Report}

During dissection of head and neck region for undergraduate medical students, bilateral variations in the branching pattern of CCA and ECA were observed in a 70 year old female cadaver.
CCA bifurcated into ECA, ICA and also gave off superior thyroid artery bilaterally in this cadaver at $2 \mathrm{~cm}$ above thyroid cartilage in right (Figure $1 \mathrm{R}$ ) and just below the level of angle of mandible at $2.5 \mathrm{~cm}$ above the upper border of thyroid cartilage on left side of neck (Figure $1 \mathrm{~L}$ ). This is a very rare variant. Immediately after originating, ECA quadrified into four branches, lingual artery, facial artery, distal ECA and occipital artery from medial to lateral side bilaterally. This is a new discovery not reported so far. Distal ECA of left side, after advancing through $3 \mathrm{~cm}$, trifurcated into three branches, posterior auricular artery, accessory artery and ECA which terminally divided into maxillary artery and superficial temporal artery. This distal trifurcation of ECA is also new. No other abnormality was observed.

\section{Discussion}

Variations of the common carotid artery include the rare absence of the common carotid artery (CAKIRER, KARAARSLAN, KAYABALI et al., 2002; MAYBODY, USZYNSKI, MORTON et al., 2003), the high or low bifurcation of the common carotid artery (HUBER, 1982) and also the abnormal branches of the common carotid artery such as the superior thyroid artery or even the thyrolingual trunk (LEMAIRE, JACQUEMIN, MEDOT et al., 2001). But anomalous bilateral trifurcation into ECA, ICA and superior thyroid artery of CCA coupled with abnormal bilateral quadrification of ECA into lingual artery, facial artery, distal ECA and occipital artery and a new trifurcation of distal ECA into posterior auricular artery, accessory artery and ECA which terminally divides in maxillary and superficial temporal arteries occurred simultaneously in the same cadaver. This configuration is reported for the first time.

But multiple anatomical anomalies in branching pattern of CCA/ECA will alter irrigation patterns and generation of 


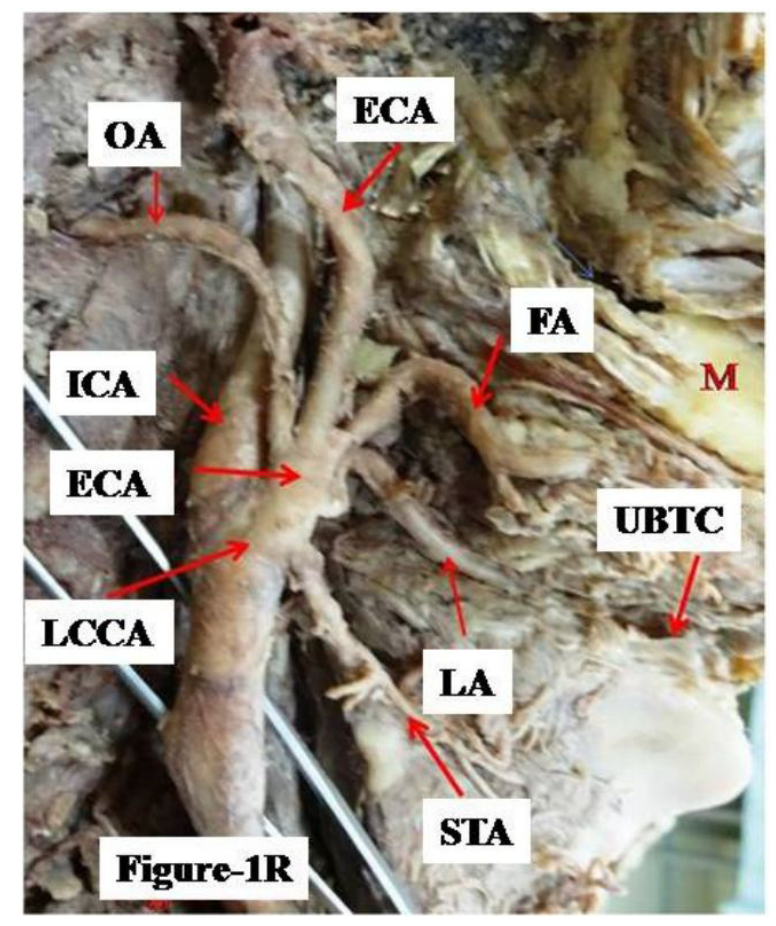

Figure 1R. Shows trifurcation of common carotid and quadrification of external carotid artery. TCCA- trifurcation of common carotid artery; STA- superior thyroid artery; ICA- internal carotid artery; QECA- Quadrification of external carotid artery; LA- lingual artery; FA- facial artery; ECA- external carotid artery; OA- occipital artery; UBTC- upper border of thyroid cartilage; M- mandible.

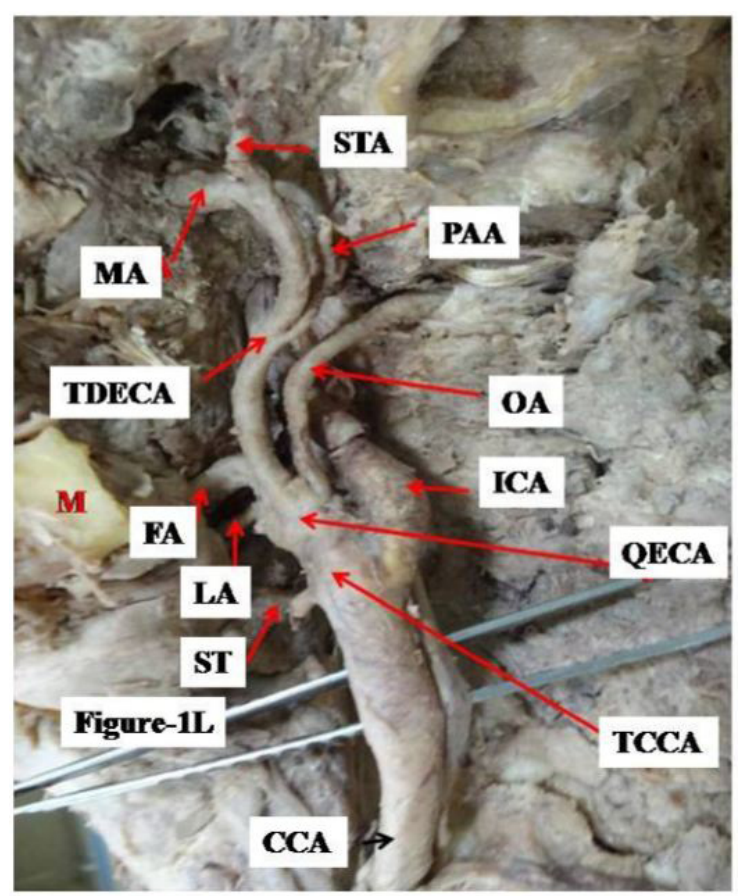

Figure 1L. Shows trifurcation of common carotid, quadrification of external carotid at the origin and trifurcation of distal external carotid artery. TCCA- trifurcation of common carotid artery; QECA- quadrification of external carotid artery; ST- superior thyroid artery; LA- lingual artery; FA- facial artery; M- mandible; TDECA- trifurcation of distal external carotid artery; MA- maxillary artery; STA- superficial temporal artery; PAA- posterior auricular artery; OA- occipital artery; ICA- internal carotid artery. biomechanical forces that cause turbulent flow and reduced shear stress / blood flow velocity (WARBOYS, AMINI, DE LUCA et al., 2011) in head and neck region. The diminution in velocity and shear stress leads to injury to the endothelium causing endothelial dysfunction. Many factors contribute to this dysfunction including high blood pressure, tobacco smoke, diabetes, and high levels of cholesterol (RIDKER, 2002) in the blood. Endothelial dysfunction disturbs the balance between vasodilatation and vasoconstriction, inhibition and stimulation of smooth muscle cell proliferation and migration, and thrombogenesis and fibrinolysis promoting/exacerbating atherosclerosis (KINLAY, LIBBY and GANZ, 2001; LUSCHER and BARTON, 1997). The presence of atherosclerosis has been established in CCA/ECA/ICA at bends and bifurcations (authors work under review with Surgical and radiological Anatomy).

Profound knowledge of variant branching pattern of carotid arteries to carry out successful removal of atherosclerotic plaques and minimize postoperative complications in a bloodless surgical field through carotid endarterectomy is unavoidable. Transcatheter embolization procedures in the external carotid artery are largely used on hypervascular tumors, epistaxis and trauma (CHITRA, 2008). Due to lack of knowledge of these variations, the misidentification of carotid arteries in radiographic evaluation or surgical proceedings could lead to fatal concequences (LUCEV, BOBINAC, MARIC et al., 2000).

\section{References}

CAKIRER, S., KARAARSLAN, E., KAYABALI, M. and ROZANES, I. Separate origins of the left internal and external carotid arteries from the aortic arch: MR angiographic findings. American Journal of Neuroradiology, 2002, vol. 23, n. 9, p. 1600-1602. PMid:12372755.

CHITRA, R. Trifurcation of the right common carotid artery. Indian Journal of Plastic Surgery: Official Publication of the Association of Plastic Surgeons of India, 2008, vol. 41, n. 1, p. 85-88. PMid:19753211. http://dx.doi.org/10.4103/0970-0358.41121.

DATTA, AK. Essential of human anatomy: head, neck and brain. 2nd ed. Current Distributors, 1989. 117 p.

HAYASHI, N., HORI, E., OHTANI, Y., OHTANI, O., KUWAYAMA, N. and ENDO, S. Surgical anatomy of the cervical carotid artery for carotid endarterectomy. Neurologia Medico-Chirurgica, 2005, vol. 45, n. 1, p. 25-30. PMid:15699617. http://dx.doi.org/10.2176/ nmc.45.25.

HUBER, P. Cerebral angiography. 4th ed. Stuttgart: Thieme, 1982.

KINLAY, S., LIBBY, P. and GANZ, P. Endothelial function and coronary artery disease. Current Opinion in Lipidology, 2001, vol. 12, n. 4, p. 383-389. PMid:1 1507322. http://dx.doi.org/10.1097/00041433200108000-00003.

LEMAIRE, V., JACQUEMIN, G., MEDOT, M. and FISSETTE, J. Thyrolingual trunk arising from the common carotid artery: a case report. Surgical and Radiologic Anatomy., 2001, vol. 23, n. 2, p. 135-137. PMid:11462863. http://dx.doi.org/10.1007/s00276001-0135-6.

LUCEV, N., BOBINAC, D., MARIC, I. and DRESCIK, I. Variations of the great arteries in the carotid triangle. Otolaryngology - Head and Neck Surgery, 2000, vol. 122, n. 4, p. 590-591. PMid:10740186.

LUSCHER, TF. and BARTON, M. Biology of the endothelium. Clinical Cardiology, 1997, vol. 20, supplement II, p. II-3-II-10.3. 
RAJANI, S.

MAYBODY, M., USZYNSKI, M., MORTON, E. and VITEK, JJ. Absence of common carotid artery: a rare vascular anomaly. American Journal of Neuroradiology, 2003, vol. 24, n. 4, p. 711713. PMid:12695210.

POYNTER, CWN. Congenital anomalies of the arteries and veins of the human body with bibliography. Lincoln. The University Studies of the University of Nebraska, 1992, vol. 22, p. 1-106.

RIDKER, M. On evolutionary biology, inflammation, infection, and the causes of atherosclerosis. Circulation, 2002, vol. 105, n. 1, p. 2-4. PMid:11772866.
STANDRING, S. (Ed.). Gray's anatomy: the anatomical basis of clinical practice. 40th ed. London: Elsevier Churchill Livingstone, 2008. p. 444-445.

WARBOYS, CM., AMINI, N., DE LUCA, A. and EVANS, PC. The role of blood flow in determining the sites of atherosclerotic plaques. F1000 Medicine Reports, 2011, vol. 3, p. 5. PMid:21654925.

Received November 2, 2015 Accepted March 18, 2017 